\title{
One patient with two uteri and two pregnancies - a rare case of twins in a patient with uterus didelphys
}

\author{
Ksawery M. Golawski ${ }^{1} \mathbb{D}$, Michal Lipa ${ }^{2} \mathbb{D}$, Robert Brawura-Biskupski-Samaha2 ${ }^{\mathbb{D}}$, \\ Iwona Szymusik² ${ }^{\mathbb{D}}$, Miroslaw Wielgos ${ }^{2} \mathbb{D}$
}

${ }^{1}$ Student's Scientific Association at the $1^{\text {st }}$ Department of Obstetrics and Gynecology, Medical University of Warsaw, Poland ${ }_{2}^{2} 7^{\text {st }}$ Department of Obstetrics and Gynecology, Medical University of Warsaw, Poland

\begin{abstract}
We report an extraordinary case of double pregnancy in patient with uterus didelphys. This anatomic anomaly originates from the lack of fusion of the paired Mullerian ducts during embryological development with $0.3 \%$ prevalence in the population. The patient presented to our department with initial diagnosis which was confirmed during ultrasound examination at 12 weeks - uterus didelphys with dichorionic diamniotic twin gestation. Further ultrasound scans were performed every 4 weeks and revealed small for gestational age fetuses. Due to the uterine malformation and the history of cesarean section, the patient was qualified for an elective cesarean section at 36 weeks of gestation - two premature neonates were delivered in good general conditions.
\end{abstract}

Key words: uterus didelphys; Mullerian duct anomalies; double pregnancy; ultrasound during pregnancy

Ginekologia Polska 2021; 92, 12: 905-906

\section{INTRODUCTION}

Mullerian duct anomalies (MDA) are congenital defects of the female genital tract that arise from abnormal embryological development [1]. One of the MDA's is uterus didelphys, commonly known as "double uteri". Uterus didelphys originates from the lack of fusion of the paired Mullerian ducts that should occur between $6^{\text {th }}$ and $11^{\text {th }}$ weeks of gestation [2]. The prevalence of uterus didelphys is assessed to be $0.3 \%$ in the population, however it may be underestimated due to the challenging diagnosis with the use of advanced three-dimensional ultrasonography [3].

\section{CASE PRESENTATION}

33-year-old patient, gravida 2, para 2, with uterus didelphys was referred to the Outpatient Clinic of Multiple Pregnancies at the $1^{\text {st }}$ Department of Obstetrics and Gynecology, Medical University of Warsaw, at 12 weeks of dichorionic diamniotic gestation for the first trimester scan. Ultrasound examination confirmed the primary diagnosis - dichorionic twins present in each of the uterine cavities (U3b according to the ESHRE/ESGE classification). First trimester screening revealed a low risk of chromosomal abnormalities for both fetuses and normal anatomy. Chorions were located on the anterior uterine wall, adherent to the septum. Further ultrasound scans, performed every 4 weeks, revealed that both fetuses were small for gestational age. Second and third trimesters of gestation were uneventful. Due to the uterine malformation and the history of cesarean section, the patient was qualified for an elective cesarean section at 36 weeks of gestation - two premature male neonates were delivered $\left(2155 \mathrm{~g} / 51 \mathrm{~cm} ; 2270 \mathrm{~g} / 47 \mathrm{~cm} ; 2^{\text {nd }}\right.$ and $6^{\text {th }}$ centile, respectively) in good general conditions. Intrapartum assessment of the uteri was corresponding to the prenatal diagnosis. Early postoperative period was uneventful and patient was discharged from our Department within 48 hours (Fig 1.).

Corresponding author:

Michal Lipa

$1^{\text {st }}$ Department of Obstetrics and Gynecology, Medical University of Warsaw

1/3 Starynkiewicza Sq., 02-015 Warsaw, Poland

e-mail: michallipa1@gmail.com

Received: 17.08.2021 Accepted: 15.09.2021 Early publication date: 21.10 .2021

This article is available in open access under Creative Common Attribution-Non-Commercial-No Derivatives 4.0 International (CC BY-NC-ND 4.0) license, allowing to download articles and share them with others as long as they credit the authors and the publisher, but without permission to change them in any way or use them commercially. 

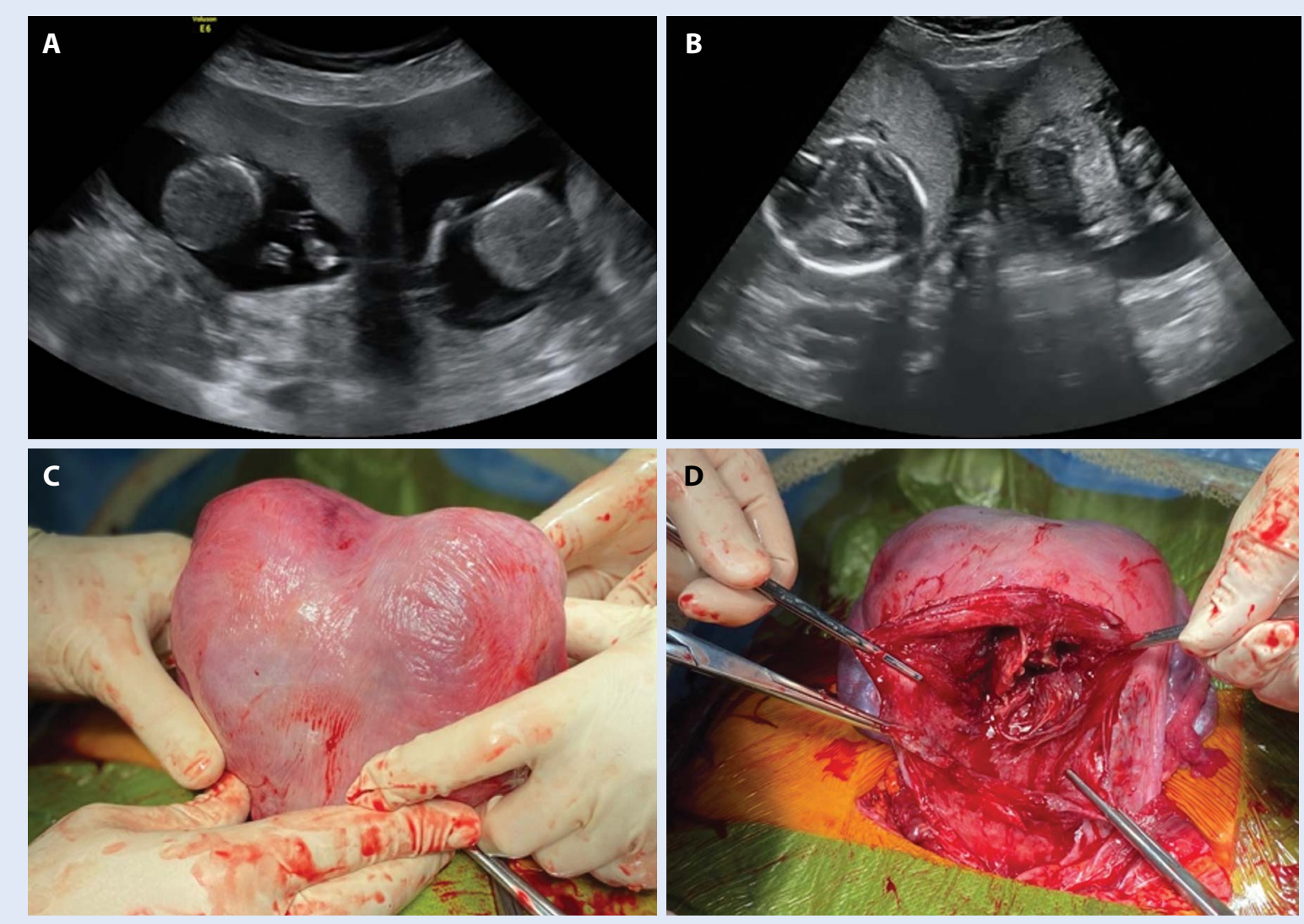

Figure 1. A. First trimester ultrasound examination; B. Second trimester ultrasound examination; C. Intraoperative presentation of the fundus of the uterus; D. Intraoperative presentation of the septum dividing the uterus into two separate uterine cavities

Patients affected with MDA remain at risk of perinatal complications due to the increased probability of preterm delivery, fetal growth restriction and malpresentation. Thus, three dimensional ultrasonographic evaluation of the uterine cavity might be an important part of preconception counselling and risk stratification. Moreover, MDA diagnosis is the key element of perinatal management and delivery planning.

\section{Conflict of interest}

There was no potential conflict of interest reported by the authors.

\section{REFERENCES}

1. Shulman LP. Müllerian Anomalies. Clinical Obstetrics \& Gynecology. 2008; 51(2): 214-222, doi: 10.1097/grf.0b013e31816feba0.

2. Troiano R, McCarthy S. Müllerian Duct Anomalies: Imaging and Clinical Issues. Radiology. 2004; 233(1): 19-34, doi: 10.1148/radiol.2331020777.

3. Chan YY, Jayaprakasan K, Zamora J, et al. The prevalence of congenital uterine anomalies in unselected and high-risk populations: a systematic review. Human Reproduction Update. 2011; 17(6): 761-771, doi: 10.1093/humupd/dmr028. 